\title{
O COOPERATIVISMO E AS AÇÕES DAS COOPERATIVAS DE CRÉDITO FRENTE ÀS CRISES ECONÔMICAS
}

Prof. Dr. Gabriel César Dias Lopes, PhD

\section{RESUMO}

Diante da crescente importância das cooperativas de crédito nas economias locais e regionais no país, busca-se com esse estudo um resgate histórico das mesmas, avaliando sua contribuição para as economias regionais e especificamente no caso onde as crises na lavoura, tem oscilações constantes que definem as ações das cooperativas. Sendo assim, esse trabalho visa através de um estudo bibliográfico historicizar as origens das cooperativas, pesquisar a atuação da cooperativa de crédito SICOOB e de que forma a mesma refletiu-se no caráter organizacional e funcional da instituição.

Palavras-Chave: Cooperativismo, Cooperativas de Crédito, Economia Regional.

\section{ABSTRACT}

In view of the growing importance of credit unions in local and regional economies in the country, this study seeks a historical rescue of them, evaluating their contribution to regional economies and specifically in the case where crises in the crop, have constant oscillations that define cooperative actions. Therefore, this work aims, through a bibliographic study, to historicize the origins of cooperatives, research the 
performance of the SICOOB credit cooperative and how it was reflected in the organizational and functional character of the institution.

Keywords: Cooperatives, Credit Unions, Regional Economy.

\section{RESUMEN}

En vista de la creciente importancia de las cooperativas de ahorro y crédito en las economías locales y regionales del país, este estudio busca un rescate histórico de ellas, evaluando su contribución a las economías regionales y específicamente en el caso donde las crisis en el cultivo, tienen oscilaciones constantes que definen acciones cooperativas Por lo tanto, este trabajo tiene como objetivo, a través de un estudio bibliográfico, historizar los orígenes de las cooperativas, investigar el desempeño de la cooperativa de crédito SICOOB y cómo se reflejó en el carácter organizacional y funcional de la institución.

Palabras clave: Cooperativas, Cooperativas de Crédito, Economía Regional.

*Gabriel César Dias Lopes é Ph.D é Graduado em: Teologia, Direito, Administração e Recursos Humanos, MBA em Marketing e Gestão Estratégica, Pós-Graduado em Psicanálise, Coordenador do Curso de Pós Graduação Lato Sensu em Psicanálise Clinica da FABIC, Mestre em Educação, Mestre em Administração, Doutor em Educação e um Ph.D em Psicanálise. Indicador Chefe, Instrutor e Autoridade do GAFM® e da American Academy of Financial Management® (oficial GAFM ® AAPM e AAFM), Membro da Comissão Científica da Olympus Intellectual Center, Atenas (Grecia), Presidente da LUI - Logos University International. Membro do Conselho Regional de Administração de Minas Gerais ID No. 


\section{INTRODUÇÃO}

A própria semântica do termo Cooperativismo revela a natureza de sua ação em todos os aspectos que seria a de colaboração e a associação de pessoas ou grupos com os mesmos interesses, a fim de obter vantagens comuns em suas atividades. No caso das cooperativas de crédito essa finalidade seriam as atividades econômicas.

O cooperativismo em sí remete à questão de necessidades comuns e essas necessidades por sua vez remete às desvantagens comuns do sistema capitalista de grupos en competição. Sendo assim a cooperação justifica-se pela necessidade de união de grupos e/ou pessoas com desvantagens afins para resolverem dificuldades em comum.

Entendendo que o cooperativismo atua no sentido de reduzir os custos de produção, obter melhores condições de prazo e preço, edificar instalações de uso comum, enfim, interferir no sistema em vigor à procura de alternativas a seus métodos e soluções, esse estudo tratará de como a cooperativa atua na região especifica buscando amenizar os impactos dessa crise.

Assim, as cooperativas de crédito durante as duas últimas décadas têm sido uma alternativa viável às pequenas cidades, pequenas economias e economias locais. São vários os casos de sucesso e em termos numéricos elas vão se expandido em todo o país.

As cooperativas de crédito são sociedades sem fins lucrativos que integram o Sistema Financeiro Nacional (SFN). Elas se destinam essencialmente a prover serviços financeiros aos seus associados.

Por ser uma região monocultora sujeita às variáveis da lavoura cacaueira, como as cooperativas de crédito subsistem a essas oscilações e de que forma se organizam para isso? Há realmente um impacto nesse sentido, ou todo funcionamento das cooperativas atendem a questões mais abrangentes?

Assim, esse estudo se justifica pela necessidade de entender a ação, organização e atuação dessa cooperativa de crédito diante das oscilações econômicas locais agravadas pela crise generalizada. E tem como objetivos 
principais,analisar a estrutura e funcionamento das cooperativas de crédito, revisar historicamente a função das cooperativas de crédito

\section{ECONOMIA E HISTÓRIA DO BRASIL: ALICERCES PARA O COOPERATIVISMO}

A história econômica contemporânea do Brasil está amplamente ligada ao desenvolvimento do liberalismo econômico filosofia que embasa o capitalismo e também o resultado da relação do desenvolvimento das forças produtivas e das forças sociais. São também o resultado da luta de classes e ao mesmo tempo contribuem para a reprodução das classes sociais.

O termo liberalismo apesar de ter surgido no século XVII, só passa a ser adotado na segunda metade do século XIX. O liberalismo econômico apoia-se no principio de que, uma vez que o interesse individual coincide com o interesse geral, deve-se na prática conceder plena liberdade de ação aos interesses privados. $O$ regime de liberdade é essencial para que o aumento do capital se processe da melhor forma, preceito que evidencia a necessidade de ser limitadas as funções do Estado.

O Estado liberal que vai substituir o Estado absolutista repousa em quatro princípios básicos: a liberdade, a igualdade política, a propriedade e a segurança; "destes a pedra angular da sociedade liberal é o direito de propriedade" (DOMINGUES, 1994: 132).

O liberalismo assim é ideologicamente visto como uma filosofia global, que abrange todos os aspectos da vida na sociedade, e se apresenta como resposta a todos os problemas que se colocam na sociedade, relativos ao respeito da liberdade, das relações entre as pessoas e de sua relação com a verdade.

Trata-se também de uma filosofia social individualista, na medida em que coloca o individuo á frente da razão de Estado dos interesses de grupo, das exigências da coletividade (...) Trata-se ainda de uma filosofia da história, de acordo com a qual a história é feita não pelas forças coletivas, mas pelos indivíduos. (DOMINGUES, 1994: 132) 
O liberalismo para alguns autores é tido como um disfarce do domínio da burguesia capitalista, impondo seus interesses, seus valores, suas crenças. Nesse sentido se reveste também da capa da democracia, mas o que há na verdade é uma luta pela soberania burguesa. A esse revestimento democrático, foi dado o nome de neo-liberalismo, que segundo René Remond, historiador francês: apoia-se em dois pilares: o dinheiro e o ensino.

O liberalismo dissimula a contradição quando apresenta essas medidas como instrumento de igualdade social, de melhoramento, do bem-estar, de igualdade de oportunidades.

Dentro desse estado contraditório do neo-liberalismo é que vão desenvolver-se as forças que originarão o cooperativismo, que apesar de ter seu surgimento análogo à Revolução Industrial, vem modificando suas formas através dos tempos e o que a princípio surge e serve para contrapor-se ao capitalismo industrial , atualmente dá bases e sustentação a esse mesmo capitalismo.

\subsection{O COOPERATIVISMO NA HISTÓRIA}

O cooperativismo enquanto necessidade da espécie humana de colaborar para sobreviver, existe desde épocas remotas." o homem é um ser social. Juntos, os indivíduos têm mais chance de sobreviver e de evoluir. Disso já sabiam os egípcios, os gregos, os romanos, os maias, os astecas. Não é à toa que eles viviam em comunidades e se uniam para caçar, pescar, construir e cultivar.

Acelerando em termos históricos, as associações que surgem na 1a․ Fase da Revolução Industrial fizeram de tudo para impedir que as máquinas tirassem o ganhapão de seus membros, mas debalde ações clandestinas violentas - como a queima das fábricas - foram reprimidas com vigor.

Ao mesmo tempo, Robert Owen, um dos pais do socialismo, começou a pregar que a indústria em si é benéfica, ao baratear os bens de consumo, mas que ela deveria ser colocada sob o controle dos trabalhadores e os resultados do trabalho em comum deveriam ser repartidos equanimemente. Ele propunha que ao redor das fábricas se formassem aldeias cooperativas, em que os meios de produção seriam possuídos e geridos coletivamente. (SCHARDONG,2003). 
Owen criou várias aldeias com este caráter, uma nos Estados Unidos e as demais na Inglaterra. Assim na terceira década do século passado, o "owenismo" tomou-se um movimento de massas na Inglaterra e passou a inspirar o nascente movimento das trade-unions. Também assumiu a liderança das lutas operárias e orientou os sindicatos a formar cooperativas de produção de cada vez que fizessem greves, tendo em vista tomar o mercado dos capitalistas, Nesta época, centenas de cooperativas foram formadas e em diversas ocasiões os sindicatos tentaram levar a cabo a estratégia de Owen. (SCHARDONG,2003).

A classe capitalista reagiu desencadeando violenta ofensiva contra as organizações dos trabalhadores: fizeram 'lock-outs', para expulsar os trabalhadores owenistas das empresas, organizaram listas negras contra o emprego de ativistas sindicais e obrigaram os empregados a assinar uma promessa de jamais se filiar a um sindicato.

Assim, parte dos sindicatos fechou e outros se tornaram clandestinos. Muitas cooperativas também encerraram suas atividades, ocasionando o declínio do movimento operário à essa época. Somente, em 1844, um pequeno número de trabalhadores industriais fundou em Rochdale, um importante centro têxtil, uma cooperativa de consumo que eles chamaram "A Sociedade dos Pioneiros Equitativos". (Eram todos militantes operários owenistas ou cartistas). (SCHARDONG,2003).

Eles adotaram oito princípios, que provavelmente decorriam da experiência das duas ou três décadas anteriores de cooperativismo. Sendo assim, Cooperativismo e sindicalismo sempre caminharam juntos, nos países europeus essa visão sempre foi associada. Em resumo estes princípios eram os seguintes:

$.1^{\circ}$ A sociedade seria governada democraticamente, cada sócio dispondo de um voto; 2ํ A sociedade seria aberta a quem dela quisesse participar, desde que integrasse uma quota de capital mínima e igual para todos;

$3^{\circ}$ Qualquer dinheiro a mais investido na cooperativa seria remunerado por uma taxa de juro, mas não daria ao seu possuidor qualquer direito adicional de decisão;

4ํㅜㄴ Tudo o que sobrasse da receita deduzidas todas as despesas, inclusive juros, seria distribuída entre os sócios em proporção às compras que fizessem da cooperativa;

$5^{\circ}$ Todas as vendas seriam à vista;

$6^{\circ}$ Os produtos vendidos seriam sempre puros e de boa qualidade;

$7^{0}$ A Sociedade deveria promover a educação dos sócios nos princípios do cooperativismo; 
8 A Sociedade seria neutra política e religiosamente.

Assim, a Sociedade dos Pioneiros de Rochdale cresceu imensamente, alcançando dezenas de milhares de sócios. Representando um importante mercado consumidor, os Pioneiros fundaram diversas cooperativas de produção: fábrica de sapatos e tamancos, fiação e tecelagem, uma cooperativa de habitação e uma sociedade de beneficência, que prestava assistência á saúde. (SCHARDONG,2003).

O exemplo de Rochdale se irradiou pela Inglaterra e mais tarde por outros países. Numerosas cooperativas foram fundadas à base daqueles princípios. Hoje, a cooperativa de Rochdale é considerada a mãe de todas as cooperativas. Surgem aí as bases do Cooperativismo tal qual temos hoje.

Em outros países, a exemplo da França, o Cooperativismo surge na mesma época, sempre ligado às lutas operárias. Na Alemanha foram desenvolvidas cooperativas de crédito rurais e urbanas, seguindo modelos diferentes, mas aplicando os mesmos princípios. Finalmente, em 1895, fundou-se a Aliança Cooperativa Internacional, que desde então congrega as entidades cooperativas de todos os países do mundo.

Assim pode-se definir Cooperativismo como um movimento econômico e social, entre pessoas, em que a cooperação se baseia na participação dos associados, nas atividades econômicas com vistas a atingir o bem comum.

Enquanto Cooperativa é aqui entendida como uma associação autônoma de pessoas que se unem, voluntariamente, para satisfazer aspirações e necessidades econômicas, sociais e culturais comuns, por meio de uma empresa de propriedade coletiva e democraticamente gerida.

Segundo a (OCB) Organização das Cooperativas do Brasil,"mais que um modelo de negócio, o cooperativismo é uma filosofia de vida que busca transformar o mundo em um lugar mais justo, feliz, equilibrado e com melhores oportunidades para todos." Nela o empoderamento do sócio e suas conquistas pessoais são tão importantes quanto o resultado, sendo que, quando a família está satisfeita e fortalecida o sucesso do empreendimento é eminente e essa é a base fundamental para uma sociedade cooperativa de sucesso. Cooperativismo é um caminho que mostra que é possível unir desenvolvimento econômico e desenvolvimento social, produtividade e sustentabilidade, o individual e o coletivo. (OCB, 2019). 


\subsection{COOPERATIVA DE CRÉDITO: O QUE É}

As cooperativas surgiram em quase todos os países, assumindo diversas formas: cooperativas de consumo - empresas de propriedade de seus clientes, que Ihes vendem bens ou serviços de qualidade comprovada a preços mínimos, pois não visam lucros. São hoje importantes em setores que fornecem serviços de grande valor, a longo prazo, como as cooperativas de saúde, escolas cooperativas, cooperativas de crédito, de seguros, habitacionais etc.; cooperativas de comercialização - empresas formadas por pequenos ou médios produtores agrícola, artesanais, coletores de refugos recicláveis, etc, que vendem a produção dos sócios e compram para eles equipamentos, matérias primas, etc. (PINHEIRO,2008).

Cooperativas agrícolas frequentemente criam indústrias de processamento de produtos agropecuários, acrescentando valor a eles; cooperativas de produção_empresas de produção coletiva agropecuária, industrial ou de serviços. Uma modalidade de cooperativa de produção são as chamadas 'cooperativas de trabalhadores' ou de 'serviços', que prestam serviços nas instalações e com os equipamentos dos clientes. São exemplos cooperativas de manutenção de redes de energia elétrica e de telefonia, de manutenção e limpeza de edifícios, hospitais, etc., e de fornecimento de mão de obra para colheitas, para confecção de vestuário, calçados, etc. (PINHEIRO, 2008).

Embora haja grandes diferenças entre os vários tipos de cooperativas, todos se regem pelos mesmos princípios, que são os herdados dos Pioneiros de Rochdale, adaptados e enriquecidos por sucessivos congressos da Aliança Cooperativa Internacional. Todas as cooperativas são democráticas e igualitárias, seus dirigentes são eleitos pelos sócios, as diretrizes são discutidas e aprovadas em assembleias gerais, nas de produção o ganho líquido é repartido conforme critérios aprovados pela maioria etc... São estes princípios que permitem distinguir falsas cooperativas das verdadeiras. (PINHEIRO,2008).

Ricciardi e Lemos (2000) conceituam o cooperativismo como uma forma de melhorar a situação econômica e de qualidade de vida de seus membros. Assim sendo, principalmente em tempo de descontrole econômico, a cooperativa objetiva visa ampliar as possibilidades de tornar esse período menos desconfortável para seus 
membros, buscando alternativas que aceleram a melhor forma de passar pelo período de crise.

Enquadrada enquanto cooperativa de consumo, a cooperativa de crédito, é segundo Schimmelfenig (2010) :

Uma instituição financeira que, como outras, oferece serviços e produtos. O que diferencia de outras instituições comerciais, é que o cooperado é o dono desse "banco" e se beneficia dessa condição com juros mais baixos, rendimentos maiores e melhor atendimento.

Este segmento de cooperativismo é uma realidade em todo o mundo, especialmente no Brasil, onde o cooperativismo de crédito experimenta um grande crescimento, bem como um forte avanço estratégico e organizacional, fato fundamental na ampliação de sua atuação no mercado financeiro do país.

Diante do cenário econômico atual, onde o crédito tem se tornado cada vez mais restrito e escasso, surge uma nova percepção sobre o cooperativismo de crédito, suas vantagens e benefícios. Buscando dinamizar seus negócios e, principalmente, conceder melhor atendimento e recursos a seus associados, as cooperativas vão criando alternativas e adequando-se às realidades locais, como é o caso da cooperativa em questão SICOOB.

\subsection{Cooperativas de crédito no Brasil}

No Brasil as cooperativas de crédito são equiparadas às instituições financeiras (Lei $n$-4.595) e seu funcionamento deve ser autorizado e regulado pelo Banco Central do Brasil. O Cooperativismo possui também legislação própria, a Lei 5.764/71 e a Lei Complementar 130/2009.

De acordo com Araújo (2011), O Brasil está atualmente como o 16ํㅡ colocado no ranking de volume de ativos administrados pelas cooperativas de crédito. As mais de 1.400 cooperativas existentes no Brasil administram ativos em torno de US\$16 bilhões, oriundos de seus quase 4 milhões de associados.

A fatia de mercado das cooperativas de crédito é em torno de $3 \%$ do total do país. O cooperativismo de crédito é representado no Brasil pelos 
sistemas SICREDI, SICOOB, UNICRED, ANCOSOL e também por Cooperativas Independentes (solteiras) não ligadas a uma Confederação.

Em 2009, o Banco Central, por meio das circulares 3438 e 3457, permitiu às Cooperativas de Crédito tornarem-se titulares de Contas de Liquidação. Desta forma as Cooperativas passaram a compensar seus próprios cheques, boletos de cobrança bancária, bem como processar TEDs e DOCs, sem a necessidade de recorrer a bancos liquidantes. Hoje, cerca de cinquenta Cooperativas de Crédito já efetuam suas liquidações, diretamente ou através de suas centrais.

De acordo com pesquisa recente que ouviu $47 \%$ das cooperativas brasileiras que atuam com micro e pequenas empresas. Cada uma delas atende cerca de 7,6 mil associados - dois terços desse total constituem potenciais clientes do Sebrae, pois agrupam, além de MPE, empreendedores individuais $(\mathrm{EI})$, produtores rurais e profissionais liberais.

De acordo com as informações das cooperativas ao levantamento, 25\% dos empresários contratam empréstimos como pessoa física, mas utilizam os recursos nos seus empreendimentos. No que diz respeito aos créditos contratados pelas MPE, o valor médio fica em $\mathrm{R} \$ 22.855$, com um prazo, na maioria, de até 12 meses. Conforme o documento, cerca de $50 \%$ dos serviços contratados pelas micro e pequenas empresas se referem a crédito, com taxas médias de juros mensais entre $1 \%$ e $6 \%$.

A pesquisa revela que $46 \%$ dos recursos usados por essas instituições são próprios. As entidades participantes do levantamento responderam que desejam ampliar o atendimento às MPE e afirmaram que atendem os pequenos negócios de forma diferenciada, com pouca burocracia e taxas de juros mais competitivas. (Fonte Agência SEBRAE).

\subsection{COOPERATIVAS DE CRÉDITO LOCAIS}

A Cooperativa de Crédito-Sicoob são geralmente fundadas por agricultores e comerciantes nas cidades e microrregiões. São constituídas por capital social subscrito e em sua maioria decorre da necessidade de financiamento de custeio agrícola, com encargos financeiros suportáveis e da liberação de um crédito mais rápido e desburocratizado. Sua criação ocorre em vários locais do país em ápices de 
crises na lavoura que atormentam principalmente as regiões internas do país mas que podem acometer a toda a população.

Funcionam com a autorização do Banco Central do Brasil e de modo geral instituem as seguintes visão, missão e valores e objetivo:

VISÃO

"Ser reconhecido como a principal instituição financeira propulsora do desenvolvimento econômico e social dos associados."

MISSÃO

"Gerar soluções financeiras adequadas e sustentáveis, por meio do cooperativismo, aos associados e às suas comunidades."

\section{VALORES}

Transparência, comprometimento, respeito, ética, solidariedade, responsabilidade.

OBJETIVO INSTITUCIONAL

"Atender as demandas financeiras dos associados com eficácia, contribuindo para o desenvolvimento sustentável regional."

Ainda segundo o SICOOB, as vantagens de ser cooperado são: participação nas sobras, atendimento personalizado, tarifas e taxas mais baixas, contribuição na integração e fortalecimento da comunidade, crédito acessível, participação nas decisões.

Dentre os serviços apresentados estão:

Extrato de conta corrente

Extrato de aplicações e poupança

Extrato de empréstimo

Transferência de valores por meio de DOC ou TED

Transferência entre contas do SICOOB

Pagamento de Boletos bancários/títulos

Pagamento de Água/Luz/Telefone

Pagamento de GPS

Informe para IRPF

Cancelamento de folha de cheque inutilizado

FUNDO GARANTIDOR DO SICOOB

Garante os depósitos por CPF

São objetos da garantia proporcionada pelo FGS os seguintes Créditos:

I - Depósitos à vista ou sacáveis mediante aviso prévio; 
II - Depósitos em contas-correntes de depósito para investimento;

III - Depósitos de poupança.

Ainda segundo dados recolhidos pelo SICOOB, A IMPORTÂNCIA DA LIVRE ADMISSÃO estão na:

Cobrança de Títulos

Recebimentos (títulos e convênios)

Seguros

Empréstimo Aposentados e Pensionistas do INSS

Domicílio Bancário

SICOOB Salário

Transferência entre contas

Aplicações Financeira

Cartões

Depósito à Vista

Financiamentos

Cheque Especial

Conta Garantida

Crédito Rural

Empréstimo

Títulos Descontados

Repasses

Cotas partes

INTERNETBANK

Consórcios

Previdência Complementar

\subsection{PRINCIPAIS OBSTÁCULOS AO COOPERATIVISMO}

O ano de 2012 foi celebrado como o Ano Internacional das Cooperativas. De lá pra cá 8 anos se passaram e nessa curta trajetória histórica das cooperativas no Brasil, talvez o maior obstáculo tenha sido a desconfiança e desconhecimento inicial dos produtores em relação à mesma, muito em função das oscilações financeiras que o país e a região viviam. 
Além de sanar as dificuldades existentes, a Cooperativa de crédito trabalha numa visão subjacente de inclusão social tendo o sistema de crédito como principal alavanca para movimentar principalmente dos pequenos produtores.

Um dos principais obstáculos apontados ao Cooperativismo é ainda a taxa de juros que segundo dados de pesquisas é mais alto para empresas que para pessoas físicas. A baixa na taxa de juros certamente será fator que desencadeará maior índice de adesão ao Cooperativismo no país.

\section{CONSIDERAÇÕES FINAIS}

O surgimento de instituições cooperativistas no seio das sociedades promove desenvolvimento humano e dissemina uma cultura baseada no capital sem os equívocos do capitalismo. Apesar da dificuldade que enfrenta em alguns ambientes onde a educação não segue na direção do coletivo, vários são os modelos exitosos nas mais diversas regiões do Brasil

O cooperativismo em sí remete à questão de necessidades comuns e essas necessidades por sua vez remete às desvantagens comuns do sistema capitalista de grupos em competição. Sendo assim a cooperação justifica-se pela necessidade de união de grupos e/ou pessoas com desvantagens afins para resolverem dificuldades em comum

Cooperativas como agentes de transformação, essa se tornou a proposta de um modelo de empresa que é formado por pessoas para pessoas e que através de seus princípios e valores muda o ambiente a sua volta, porém é necessário muita persistência e compromisso dos gestores para promover educação e mudar conceitos pois, vivenciar um modelo que nos impõe mudanças ético-morais na atualidade com uma sociedade adoecida de valores não é tarefa simples. 


\section{REFERENCIAS}

ARAÚJO, Elisson Alberto Tavares; Silva, Wendel Alex Castro. (janeiro/junho 2011). "Cooperativas de Crédito:a Evolução dos Principais Sistemas Brasileiros com um Enfoque em Indicadores Econômico-Financeiros" (em português). Contextus - Revista Contemporânea de Economia e Gestão 9 (1): 117-126. Benfica, Fortaleza-CE: $\quad$ FEAAC/UFC. ISSN 21789258. OCLC 750897389.

DOMINGUES, Nadir .O uso dos conceitos : uma questao de interdisciplinaridade / Edição 4.ed. Petrópolis : Vozes, 1994. OCB. O que é, o que faz e o que pode fazer o cooperativismo no Brasil. Brasília,2019.

PINHEIRO, Marcos Antonio Henriques. Cooperativas de Crédito História da evolução normativa no Brasil. 6a․ Ed. Banco Central do Brasil. Brasília. 2008.

RICCIARDI, Luiz; LEMOS, Roberto Jenkins de. Cooperativa, a empresa do século XXI: Como os países em desenvolvimento podem chegar a desenvolvidos. São Paulo: LTr, 2000.

SCHIMMELFENIG. Cristiano. Cooperativismo de crédito: uma tendência.Revista de Administração e Ciências Contábeis IDEAU ISSN 1809-6212 Vol.5 - n.10 - Janeiro - Junho 2010 Semestral

SCHARDONG, Ademar. Cooperativa de crédito: instrumento de organização econômica da sociedade. 2 ed. Porto Alegre: Rigel, 2003

http://www.sicoobcentralcecresp.org.br/Cooperativa de Credit o.aspx. Disponível em 15 de junho de 2012 